\title{
From abstract to relevant: encouraging access to journals
}

\author{
Judith Keene
}

\section{Author}

Dr Judith Keene is currently Joint Head of LIS Research at University College Worcester, and was previously the team leader for Academic Liaison, Humanities and Social Sciences.

E-mail: j.keene@worc.ac.uk

\begin{abstract}
The article discusses and evaluates a project designed to gain understanding of students' attitudes towards using journals in their academic assignments, based on evidence that some students made little use of journals and library-run training opportunities.
\end{abstract}

Results of a questionnaire showed that students generally had a positive view of journals, but there were numerous remarks about the difficulty of accessing relevant material. Tutors have a large influence in students' perception and use of journals. Students from different subjects accessed journals in different ways, but students who had been on workshops were more likely to use an electronic index. However, many former workshop attendees still had limited confidence in finding journal articles, and a model of repeated skills development is proposed.

Implications for resource acquisition and access are discussed and the importance of working with academics to promote and deliver skills workshops is stressed. It is suggested that an institutional Information and IT Literacy policy would be helpful in developing and embedding an ongoing skills development programme.

\section{Occasion}

The research was made possible through an Elsevier/LIRG research award in 2002.

\section{Acknowledgment}

The author would like to thank LIRG and Elsevier for the opportunity to carry out this research. She is also very grateful for the help with statistical analysis given by John Colvin and John Price from the Business School, University College Worcester, and for the co-operation of academic staff throughout the project.

\section{Introduction}

This article discusses and evaluates a project carried out in the academic year 2002-03 at University College Worcester (UCW). The aim was to understand students' attitudes towards accessing the journals literature in order to review the effectiveness of current skills teaching methods.

\section{Background}


UCW is a relatively small, teaching-led institution with about 4500 students (FTE) at the time of the project. The student community is diverse, with a large number of part time and older students ( $47 \%$ and $58.8 \%$ respectively), and high retention rates. The small size is a benefit to library staff wanting to liaise effectively with staff and students, but gives us challenges in providing a diverse information base with a relatively small budget.

During the academic year 2000-2001, the Library faculty teams ${ }^{1}$ carried out a review of the use made of printed journals, in order to assess their cost- effectiveness. (At the time there was very limited access to e-journals). The process included citations analysis of all written assignments submitted by undergraduates over the year in four subject areas: Biological Sciences, Health studies, History and Psychology. It was found that the amount of use made of journals varied considerably between subjects, in line with previous studies of established scholars (e.g. Hart, 1997). The lowest use was by History undergraduates, who only cited journals in $27 \%$ of assignments at Level 1 (equivalent to the first year of a full time undergraduate course) and in $47 \%$ of level 2 assignments (equivalent to years 2 and 3).

During the same year, information skills sessions run for history students on how to access journals literature (via Historical Abstracts etc.) were poorly attended, particularly follow-up "drop-in" sessions aimed at giving hands-on practice. Other subject areas experienced more positive take-up. The teams did not understand the factors which were causing some students to reject these sessions.

These findings, especially with regard to History, caused us considerable concern for several reasons. Firstly, the Library was moving towards an "access, not holdings" policy, which relied upon students using, and being able to use, bibliographic tools to locate resources. Secondly, a relatively large proportion of the library budget was spent upon journals and bibliographic databases, and the results suggested that this spending was not cost-effective in certain subject areas. Thirdly, as at many Higher Education libraries, considerable importance was placed on Information Literacy training, and a large proportion of time given to planning and delivering sessions. Indeed, the hours spent delivering skills sessions had risen by $61 \%$ over 3 academic years. The Library was concerned to find ways to make these sessions attractive and relevant to students.

There were therefore several questions about what prompted students to use, or not use periodical literature:

- Did they simply fail to recognise the usefulness of journal literature?

- Were they using the bibliographic tools, and if not, was it because they couldn't use them effectively, or didn't choose to use them?

- Was there a correlation between high take up of skills sessions, and a positive attitude towards them on the part of the tutors?

- Were the skills sessions we offered appropriate in terms of timing and content?

\section{Literature review}

\footnotetext{
${ }^{1}$ Peirson Library, University College Worcester, now part of the Department of Information Learning Services
} 
A search was made for papers which looked either at students' attitudes to journals, or the effectiveness of Information Literacy training.

\section{Students' attitudes}

There is an assumption inherent in the literature that journals are an integral part of an academic library and essential to undergraduate study. However, no papers were found presenting evidence that students share this opinion. The studies reviewed concentrated either on how to measure the use made of resources (e.g. Sweeney, 1999 Callison, 1997), or the results of such measurement (e.g. De Groote and Dorsch, 2003, Wozar and Worona, 2003) without questioning the underlying student attitudes. There is a recognition that different disciplines use resources differently (Tenopir, 2003). In the last few years, many studies have been conducted to find out the preferred format for journals, again without questioning why they are used at all. Tenopir (2003) provides a brief review and useful links to user studies looking at this area. These studies generally confirm that students prefer online journals to print, as does the JISC funded JUBILEE project (Third Annual report of the JUBILEE project, 2003), though Tenopir points out that "college and high-school students use the Internet more than the library".

The studies which discuss the use made of library facilities or resources generally concentrate on a discrete group of users, with relatively few looking at undergraduates. Where journals use is mentioned, there is evidence going back several decades to suggest that they are often among the least used forms of information. Callison found in the late 1980s that students tended to value books above journals, and that "students were clearly in need of additional direction in understanding the potential value of journal information" (Callison 1997). Cogdill and Moore (cited in De Groote and Dorsch 2003) investigated first year medical students and found reliance on textbooks and that "one of the last places students looked for information was the journals literature". This study only looked at first years, and in fact no studies have been found which compare the information use of students across different years of study. Martin (2003) found evidence that Graduate Entry Students entering a medical course made greater use of library facilities, including journals, than undergraduate medical students, and considered this due to their greater awareness and confidence in using resources, along with the more webbased nature of their course. However, journals were still among the least used resources overall.

A few studies have looked at the use made of journals subsequent to graduation. Powell and Case-Smith (2003) surveyed occupational therapists, who ranked journals as one of the less useful forms of information in their working lives, preferring to use more readily available forms of information. Wozar and Worona (2003) also found limited use of journals compared to other resources in their small sample. However, both of these studies focused on health practitioners who were more interested in resources to support care of patients than research materials. 


\section{Effectiveness of training}

Much of the work has been carried out with nursing students or other health professionals, the results of which cannot be assumed to relate directly to other groups of students. Garg and Turtle (2003) have written a useful review of these studies, from which they conclude that many are methodologically weak. The three studies that met their criteria indicated that training does lead to an improvement in retrieval skills, and that it is generally considered useful by the recipients. The degree of improvement and the longer term effects of the training could not be assessed from the studies. Powell and Case-Smith (2003) highlight the difficulty of proving effectiveness of any programme, because of the many variables impacting upon both it and the institution.

Grimes and Charters (2000) found that students who had had training spent significantly less time in the library, which he believed was consistent with a greater efficiency in time use. A recent study of computing students by Colvin and Keene (2004) found evidence for an increase in the use of e-journals following promotion of and training in relevant resources.

One of the intentions of training is to promote habits of lifelong learning in students, and there is limited evidence that this occurs. Powell and Case-Smith (2003) refer to a study by Fox who found that graduates who completed library instruction subsequently read more journals and participate earlier in scholarly activity. A survey by Kennedy in 1991 (cited in Powell and Case-Smith 2003) concluded that bibliographic training had had some influence on graduates' information seeking and use. Wozar and Worona (2003) monitored use of electronic resources by nurses following training, and concluded that nurses will use online resources once they are made available, and that "larger scale library outreach programmes ... would be useful".

It seems therefore that there is limited evidence that training can lead to increased use of resources and greater ability and efficiency in retrieving information.

\section{Methodology}

Previous projects at the Peirson Library had shown that it was extremely difficult to attract students to participate in focus groups. Therefore, a questionnaire approach was initially taken; targeting students in the same four subject areas as previously. It was hoped that the quantitative information gained might then inform focuses for further qualitative information gathering. Students' attitudes were explored by asking questions about which resources they used and why, how they accessed them, and their perceptions of their need for skills teaching. In order to maximise the returns, a paper format was used and tutors' co-operation was sought to distribute the questionnaires during teaching time, where possible in mandatory modules. Both daytime and evening modules were targeted, in order to access a cross section of full and part time students. Records of past information skills were studied to identify which students had been exposed to skills teaching, and when this had occurred.

Initial analysis of the questionnaires indicated that students claimed to use journals far more than the citations analysis evidence had suggested. It was therefore decided to carry out some further limited citations analysis in case there had been significant changes since the earlier study. Where possible, usage figures were collected for 
relevant database use as another strand of evidence. However, it was not the main purpose of this study to quantify student resource use although it would be interesting to supplement the questionnaire findings by interviews and observations in the next academic year.

\section{Results}

\section{Questionnaires}

352 questionnaires were analysed using SPSS, representing:

$43 \%$ of undergraduate biology students

$29 \%$ of health

$52 \%$ of history

$39 \%$ of psychology

26 questionnaires were from students taking other courses of study, and were discarded.

There was approximately the same number of returns from each year group, and the age distribution reflected the college population well (37.5\% of the sample who gave their age were under 21 , compared to 41.8 of the UCW population). However, only $10.5 \%$ of the sample overall were part time compared to $22 \%$ of the UCW students.

The good coverage across subjects and ages was largely due to the use of paper questionnaires, which could be distributed and collected in targeted modules, ensuring a high response level. However, one disadvantage of the paper format was the ability for respondents to answer questions incorrectly, for instance by leaving out questions, or ticking the wrong number of boxes. A web-based questionnaire could be designed to largely eliminate these problems.

\section{Resource use}

Books were the most frequently used resources, with $93.2 \%$ of respondents claiming that they always use them and $99.1 \%$ always or sometimes using them. Other studies carried out in institutions before subscribing to online full text services have found a similar preference for books (Callison, 1997). Web pages were the second most used resources ( $42 \%$ always, $90.1 \%$ sometimes or always), then journals (37.3\% always, $80.9 \%$ sometimes or always). E-journals, (of which there are relatively few subscribed to by UCW at present), were least used but $17.3 \%$ claimed to use them always and $64.2 \%$ sometimes or always.

When looked at by year of study, there was a pattern of rising journals use over the three years (Fig.1). By year3, all students claimed to use journals at least sometimes, and $81 \%$ of respondents thought that journals were useful at least sometimes. 


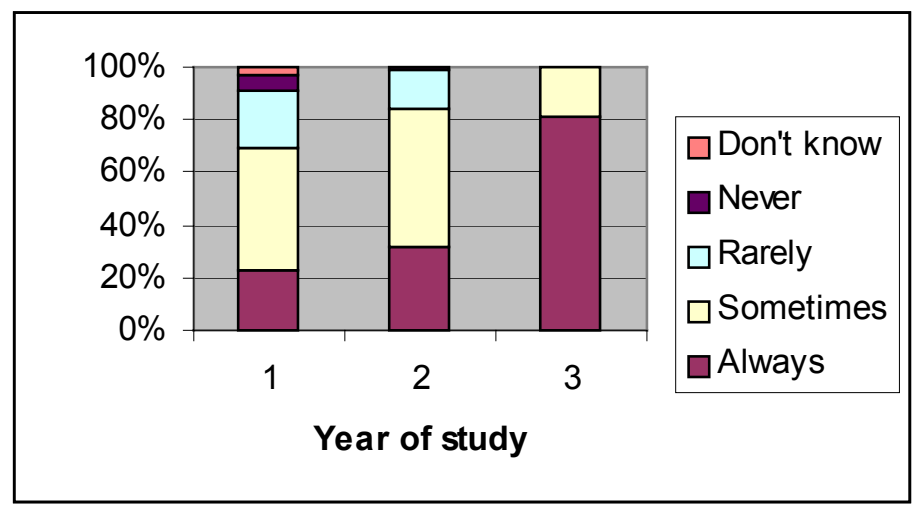

Figure 1: Claimed use of journals by year of study.

The high use claimed for journals appeared to conflict with evidence from the earlier citations analysis, particularly when analysed by subject. $88.1 \%$ of history students claimed that they used journals always or sometimes, more than any other subject area. However in the citations analysis, they had shown the lowest average use of journals per assignment.

The questionnaire also asked whether students thought their tutors expected them to use journals for their assignments. Only 13 respondents overall answered "rarely", "never" or "don't know", indicating that tutors do communicate a high expectation of journals use in all subject areas. In Biology, Health and History, the majority answered that they were "sometimes" expected to use journals in years 1 and 2, and "always" in year 3. However in Psychology, the majority answered "always" in all 3 years. Overall, there is a pattern of increasing expectation of journals use in each successive year group (figure 2).

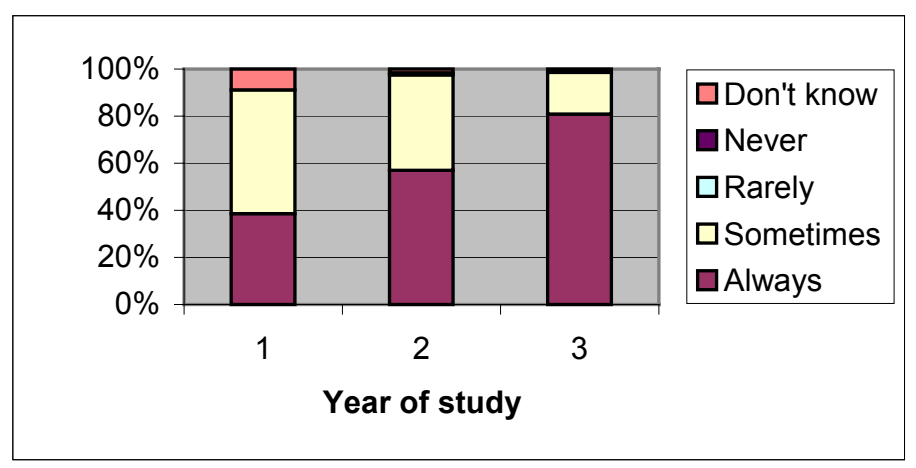

Figure 2: Responses to the question: "Do you think that your tutors expect you to use journals for your assignments?"

Non-users of journals were invited to explain why, and there were 53 responses from both users and non-users. These proved to be very informative. 8 respondents said they hadn't yet felt the need to use journals, and 7 found problems with the content it turned out to be irrelevant, too difficult, or not specific enough. The other responses fell into several areas: 
- uncertainty in how to search (mainly, but not entirely from respondents who hadn't been to workshops)

- difficulties in finding relevant material, including frustrations with the range held by the library (this included students who had been to workshops and were claiming to make frequent use of journals)

- too time consuming.

\section{Methods of searching}

Overall, students claimed that using module reading lists was the most used method of finding journals (63.4\% of respondents), with browsing a close second $(62.2 \%)$. The data are shown in Table 1.

\begin{tabular}{|l|l|l|l|l|}
\hline & Biology & Health & History & Psychology \\
\hline Reading list & 22 & 24 & 68 & 95 \\
\hline Ask a friend & 9 & 15 & 26 & 51 \\
\hline $\begin{array}{l}\text { Browse the } \\
\text { journals }\end{array}$ & 16 & 36 & 58 & 92 \\
\hline $\begin{array}{l}\text { Electronic } \\
\text { Index }\end{array}$ & 21 & 20 & 55 & 82 \\
\hline Ask a librarian & 7 & 12 & 33 & 27 \\
\hline Ask a tutor & 3 & 4 & 21 & 20 \\
\hline
\end{tabular}

Table 1: Numbers of students (by subject) using different search methods to find journal articles

2-way analysis of variance was used to establish at the 5\% level whether the data suggested that students from different subject areas researched differently. The calculated figure of 19.24 compared to a table value $F(3,15)$ of 3.29 . This suggests that the null hypothesis must be rejected at the $5 \%$ level and that there are differences between subjects in the ways students claim to search. The data are also significant at the $1 \%$ level.

Compared to the average figures, Biologists were much less likely to browse, but were slightly more likely to use electronic indexes. Health students were low users of both reading lists and electronic indexes. History students were very likely to use passive search techniques - using reading lists, or asking librarians and tutors for ideas. Surprisingly in the light of research (Delgadillo and Lynch, 1999) and of comments from history tutors at UCW, they were only average browsers.

Psychologists were heavy users of reading lists, browsing and electronic indexes.

The influence of tutors was therefore demonstrated again by the heavy reliance on reading lists by most students. Success is almost guaranteed with this method (provided the tutors cite the references correctly), reflected by the $96 \%$ of respondents who were happy with it as a technique. The reasons for the popularity of browsing are less obvious, though $89.2 \%$ found it very or reasonably successful. This could be an interesting subject for further investigation. 
Half the respondents claimed to use electronic indexes. Significance testing was used to establish whether the data (Table 2) suggested that attending a workshop influenced the use of an electronic index by students.

\begin{tabular}{|l|l|l|l|}
\hline & Claims to use index & Does not use index & Total \\
\hline Been to workshop & 110 & 47 & 157 \\
\hline $\begin{array}{l}\text { Not been to } \\
\text { workshop }\end{array}$ & 68 & 97 & 165 \\
\hline Total & 178 & 144 & 322 \\
\hline
\end{tabular}

Table 2: attendance at workshops and subsequent use of electronic indexes

The null hypothesis, alternative hypothesis and significance levels are formally stated below:

$$
\begin{aligned}
& \mathrm{H}_{\mathrm{O}}: \mathrm{O}=\mathrm{E} \\
& \mathrm{H}_{\mathrm{A}}: \mathrm{O} \neq \mathrm{E}
\end{aligned}
$$

Significance level 5\%

The calculated value of $\chi^{2}$ is 27.1 , compared to a table value $(\mathrm{df}=1)$ of 3.84 . This suggests that the null hypothesis must be rejected at the $5 \%$ level and that attendance at a workshop does influence subsequent use (or claimed use) of electronic indexes. The data are also significant at the $0.1 \%$ level.

\section{Workshops}

A number of questions were asked about whether students had been to workshops on how to find journals, their usefulness and timing. Roughly half of the respondents overall had been to workshops, with the highest number in Psychology ( $64 \%$ of those who answered the question).

Of those who had been to workshops, the majority felt fairly or very confident at finding journals. However, $14.1 \%$ overall felt not at all confident - though many of these felt the workshop had helped a little. The figures varied to some extent across the subjects, with the biologists the least confident. Through a flaw in the questionnaire design, the students who had not been to workshops were not asked about their confidence, so no direct comparison could be made. With regards to helpfulness, $67.7 \%$ felt that the workshop had been fairly helpful, with $10.8 \%$ saying it was not at all helpful. The vast majority $(82.4 \%)$ had had the workshop early on in the first year, but although $60.4 \%$ felt the timing had only been fairly useful, $64.7 \%$ felt this was the best time to hold it - an apparent contradiction that is discussed below. There were some respondents who ticked several boxes, indicating that they would appreciate an initial session, followed up later in their course, and a few who favoured 'drop-in' sessions which they could attend at a time of choice.

Of those who had not or did not know if they had been to a workshop, $89 \%$ thought it would help, and $81 \%$ wanted it at the start of the course - it is worth noting that the majority of these probably had had the option of such a course at that time (see Table 3). 


\section{Past information skills}

Table 3 shows the pattern of skills sessions concentrating on finding information in journals delivered to the four subject areas. It demonstrates that most students (with the exception of Health) have had the opportunity of such training as part of mandatory modules in the last few academic years (though as indicated, students do not always choose to attend. There has been a shift in both History and Biology to introducing these skills early on in the students' University career.

\begin{tabular}{|c|c|c|c|c|}
\hline $\begin{array}{rr}\begin{array}{r}\text { Academic } \\
\text { year }\end{array} \\
\text { Subject }\end{array}$ & 1999-2000 & $2000-01$ & 2001-02 & 2002-03 \\
\hline Biology & $\begin{array}{l}\text { Level } 1 \text { sign up } \\
\text { sessions } \\
\text { Some level } 2\end{array}$ & $\begin{array}{l}\text { Level } 1 \\
\text { (mandatory } \\
\text { module) } \\
\text { Some level } 2\end{array}$ & $\begin{array}{l}\text { Level } 1 \\
\text { (mandatory } \\
\text { module) }\end{array}$ & $\begin{array}{l}\text { Level 1 } \\
\text { (mandatory } \\
\text { module) }\end{array}$ \\
\hline Health & Some level 2 & - & $\begin{array}{l}\text { Level } 1 \\
\text { Some level } 2\end{array}$ & ?Level 1 \\
\hline History & Level 2 & Level 2 & $\begin{array}{l}\text { Level } 1 \\
\text { (mandatory } \\
\text { module) (poor } \\
\text { take up) }\end{array}$ & $\begin{array}{l}\text { Level } 1 \\
\text { (mandatory } \\
\text { module) }\end{array}$ \\
\hline Psychology & $\begin{array}{l}\text { Level } 1 \\
\text { (mandatory } \\
\text { module) }\end{array}$ & $\begin{array}{l}\text { Level } 1 \\
\text { (mandatory } \\
\text { module) }\end{array}$ & $\begin{array}{l}\text { Level } 1 \text { (poor } \\
\text { attendance) } \\
\text { (mandatory } \\
\text { module) }\end{array}$ & $\begin{array}{l}\text { Level } 1 \text { (low } \\
\text { attendance) } \\
\text { (mandatory } \\
\text { module) } \\
\text { Some level } 2\end{array}$ \\
\hline
\end{tabular}

Table 3: Delivery of skills sessions on finding information in journals

It is interesting to note that alongside their patchier skills teaching provision, fewer Health students ticked the "always" or "sometimes use journals" than any other subject area, and they also had the lowest claimed use of electronic indexes. However, the citations analysis indicated that they were relatively high users of journals.

\section{Citations analysis}

Tutors' help was sought in order to collect a small sample of student bibliographies to compare with the earlier analysis, and with the student answers to the questionnaire. There was a response from History and Psychology (level 1) and Health (level 2).

History: 2 out of 25 ( $8 \%$ ) bibliographies contained a single journal reference each. This was a lower incidence even than in the earlier study, in which $27 \%$ of level 1 assignments cited journals. Psychology: $71 \%$ of 51 bibliographies contained 1 or more journal references: 37 different journal titles were cited. Students taking this 
module were strongly encouraged through an earlier formative assessment process to include journal articles, so this figure may be artificially high. We do not have a figure from the earlier study for comparison. Health: 83\% of 18 bibliographies contained journal articles, compared to $68 \%$ in the earlier study.

These figures have not been statistically analysed given the small and unrepresentative samples involved, but it is interesting to note the high figure for Psychology following encouragement from tutors to use journals, the low figure for History apparently at odds with the questionnaire result, and the consistently higher figures for Health in both this sample and the earlier study.

\section{Use of journals databases}

Usage figures for Historical Abstracts and PsycInfo were collected (Table 4), but were of limited use, largely due to the difficulty of determining which users are using which databases. However, the assumption was made that Historical Abstracts in particular was likely to be used almost exclusively by staff and students in the History Department. If this is the case, it is only being used on average less than 3 times per year per member of the Department (based on 82 students in 2002-03). The much larger usage figures for PsycInfo suggest that Psychology students may make greater use of databases than History students (There were 339 Psychology students in 200203), though students in other subject areas also use PsycInfo. There is no obvious reason for the surge in use of PsycInfo in 2002-03. No databases could be identified that would be primarily used by Health or Biology students.

\begin{tabular}{|r|l|l|l|}
\hline Academic year & $\mathbf{2 0 0 0 - 0 1}$ & $\mathbf{2 0 0 1 - 0 2}$ & $\mathbf{2 0 0 2 - 0 3}$ \\
\hline $\begin{array}{r}\text { Historical Abstracts } \\
\text { No. of times accessed }\end{array}$ & 460 & 702 & 525 \\
\hline $\begin{array}{r}\text { PsycInfo } \\
\text { No. of times accessed }\end{array}$ & 2339 & 2375 & 4204 \\
\hline
\end{tabular}

Table 4. Use made of electronic indexes

\section{Discussion}

The four original questions are discussed below.

Did they simply fail to recognise the usefulness of journal literature?

The responses in the questionnaire give a consistent picture of a positive attitude towards journals on the part of students in all subject areas. They believe that they should be using journals in their academic assignments, particularly in later years of study, and they also claim to recognise the usefulness of using journals even though they identified numerous difficulties to do with locating suitable material.

There is evidence that tutors play an extremely important role in the promotion of journals to their students, through their expressed expectations and provision of reading lists. Therefore, library staff involved in information skills sessions need to ensure that they work with tutors in order to engage the students. A forthcoming staff 
development session will seek to identify some of the practices presently occurring within departments which might contribute to the differences in student perception.

Were the students using the bibliographic tools, and if not, was it because they couldn't use them effectively, or didn't choose to use them?

The two most used methods of searching, according to respondents, were using reading lists and browsing the journals. Whilst usage figures show that some databases are quite well used, others, notably Historical Abstracts, currently receive a low level of use. This is consistent with, for instance, Delgadillo and Lynch (1999), who found that browsing is important to humanities scholars, and that they were slow compared to other subject areas to use electronic search means. We know that History tutors promote browsing as a method, having pushed the library to place all history journals on open access to facilitate it. It is possible therefore that academic encouragement is important in persuading students to use databases.

Students who attended a workshop were significantly more likely to claim to use an electronic index than those who did not, in all subject areas. This suggests that all trainers involved were successfully introducing the concepts of database use. Whilst some did not use indexes because they did not know how, written comments also indicate the frustration that students experience in finding relevant material, and suggest that some choose not to use them. This contrasts with their willingness to use the Internet for assignments, as indicated by the questionnaire. The time consuming aspect of finding or accessing journals also appears to be a factor, and again contrasts with the instant access of web pages.

It appears that we need to revisit the strategy of access not holdings and consider diverting resources from indexing tools to full text options. These have the potential to allow greater success in retrieving information and the instant access that students are coming to expect, in line with "the principle of least effort". This is discussed with regard to e-journal access by Chrzastowski (1999) who says that "library patrons ... appreciate, then become addicted to, the convenient and immediate connection to needed, recent articles."

Was there a correlation between high take up of skills sessions, and a positive attitude towards them on the part of the tutors?

Published literature e.g. Roberts (2001), Colvin and Keene (2004) supports the belief that students are more receptive to skills teaching when it is embedded in the curriculum and supported by academic staff. It appears from questionnaire evidence that large numbers of students are currently failing to attend sessions, even those who should be attending as part of mandatory modules. This was useful information for us, but because data on the attitude of the academics has not yet been acquired, further work is needed to explore the causes of attendance / non-attendance.

As well as exploring the attitude of academics, we need to recognise that other factors are almost certainly at play in non-attendance, since this is a perennial problem in all disciplines, not just library sessions. This implies that although library training is linked to compulsory modules wherever possible, this will not be enough to ensure attendance. The modular structure itself can be a hindrance, since some students will have encountered library training in another module or subject area, and decide there is no benefit to attending a further session, particularly if it is perceived as irrelevant to the assessment of the module. 
The success of the e-journals promotion by Colvin and Keene (2004) was attributed to a variety of factors, including championing before and after the library input by the academic tutor, delivery of the induction session at a key time in the module, and a requirement to use e-journals in the subsequent assessment. The learning outcomes of the training therefore related to the outcomes of the module. These factors are not characteristic of the majority of workshops at present, and their lack may contribute to the relatively poor attendance. If this is so, the implication is that we need to find ways to work more collaboratively with tutors, not just to provide the sessions at their request, but to encourage them to take ownership of the sessions. We may need also to promote them and embed them more effectively, in a way that persuades students of the benefit of attending them.

Were the skills sessions we offered appropriate in terms of timing and content?

The questionnaire data indicate that workshops raise awareness of journals and increase the likelihood that students will subsequently make use of electronic indexes. On the negative side, it appears that many students are failing to recognise the usefulness of sessions in advance, so are failing to attend as discussed above. It also emerged that many students who do attend do not find the workshops in their present format as useful or timely as we might hope. This is despite the fact that most students received training at their preferred time, at the start of their first year. Possible reasons could be differing effectiveness of the trainers, differing appropriateness and effectiveness of the resources available in the various subject areas, or because the beginning of the course is not an appropriate time for the workshops, despite what the students think.

The effectiveness of the trainers is not possible to assess from this study, and would need to be followed up by other means. However, the proportions of students reporting an increase in confidence following the workshops was similar in all subjects, so it does not seem likely that this is a major factor. It is possible that subsequent frustrations with using the resources, and the lack of associated print holdings may lead to students downplaying the perceived usefulness of sessions in retrospect. This could be tested by asking students to assess the session immediately after it took place, and again after an interval of time.

The third possibility is that the timing is wrong, despite the students' preference for early training. This can be looked at from two aspects: is the timing too early, before most students are really using journals? Or is the one-off session approach inadequate?

With regard to timing, the evidence presented in figures 1 and 2 shows that at least some first-year students claim to find journals useful, and $40 \%$ feel an expectation that they will use them. There is therefore an argument in favour of providing students with at least some basic instruction in finding them. There is also pressure from academic staff to train first years, and as mentioned, the pattern has been for this to be delivered increasingly early. From experience, students often lack an understanding of the nature of journals and why they are more appropriate to academic work than (for instance) unrefereed websites. We need to be involving academic staff to work with us to explain and demonstrate the use of journals to their students, so they are able to gain confidence in using them appropriately. A recent study by Powis (2004) shows that the influence of academic staff is very important in 
determining which resources are used by students. The introduction of e-journals also gives us the option of introducing first years to the relatively easy-to-access full text resources, and leaving the question of databases to a later stage, perhaps when students are preparing for dissertations.

The students' responses also suggest that confidence in finding journals takes time, and the skills required need to be embedded over a period of time through repeated practice and use. Unfortunately, there is usually only a single session offered, with no follow up or reinforcement, and usually no link to assessment to encourage the students to apply the skills learned. Again, this might be addressed by offering an introductory orientation session early in the course, followed at intervals by further sessions. The ILS liaison team have developed 'Info Audit' tools, print and online, to help to assess the level of skills acquired and the need for further support. These tools could be useful in assessing the success of this model of training.

In order to encourage academic departments to adopt this programme within their busy teaching schedules, it would be very helpful to have an institutional policy with regard to Information and IT Literacy. This is in fact an objective within the current ILS Strategic Plan.

\section{Conclusions}

The underlying hypothesis to this project was that many students do not use journals, though the questionnaire respondents claimed this was not the case. However, the questionnaire was not designed to measure resource use, but rather the respondents' attitudes towards journals. The apparent discrepancy between student perceptions and the evidence from other sources such as citations analysis and database use, does indicate that a questionnaire would be an inadequate method of data collection for finding out what students really do use. Writers such as Callison (1997) have suggested that a case study approach utilising observations and interviews is more useful in user studies, and it would be interesting to employ this in the future.

The questionnaire did successfully explore the attitudes of students to journals and their perceptions of their tutors' expectations. It also revealed that the workshops in their present form are not as successful as we would probably wish in engaging the students. Whilst there is evidence that they raise awareness of journals and electronic retrieval methods, they are not currently instilling high levels of confidence in the students.

It was suggested in the proposal for project funding that outcomes would include:

- A strategy to increase the use of the journals literature by under-using groups of students, which will include timely, targeted information skills sessions

- Closer liaison with academic staff to encourage journals' use.

Results from the project have confirmed that these factors are closely linked and both need to be addressed. In addition, we need to look at the whole issue of access to resources, by considering making more full text resources available and by ensuring that access to them is as streamlined and simple as possible. Experience from previous projects will be useful in encouraging the take-up of online resources. 
No one group was identified by this project as under-using journals, however, the need to embed a progressive programme of information skills with the cooperation and involvement of the academic staff is confirmed. It is hoped that this will be facilitated by the commitment in the current ILS Strategic Plan to develop a college wide policy for Information and IT Literacy with stakeholders. This will then need to be actively promoted to students and staff alike.

\section{References}

Callison, D. (1997) Evolution of methods to measure student information use, Library and Information Science Research 19(4), 347-357.

Chrzastowski, T.E. (1999) E-journal access: the online access: the online catalog (856 field), Web lists, and "The principle of least effort", Library Computing 18(4), 317 322.

Colvin, J. \& Keene, J. (2004) Supporting undergraduate learning through the collaborative promotion of e-journals by library and academic departments, Information Research 9(2) paper 173 Available at http://InformationR.net/ir/92/paper173.html [Accessed 4 May 2004]

De Groote, S.L. and Dorsch, J.L. (2003) Measuring use patterns of online journals and databases, Journal of the Medical Library Association 91(2), 231-240.

Delgadillo, R. and Lynch, B.P. (1999) Future historians: their quest for information, College and Research Libraries 60(3), 245-259.

Grimes, P.W. and Charters, M.F. (2000) Library use and the undergraduate economics student, College Student Journal, 34(4), 557-568.

Hart, R.L. (1997) Information gathering among the Faculty of a comprehensive college: formality and globality, Journal of Academic Librarianship 23(1), 21-27.

Martin, S. (2003) Impact of a Graduate Entry Programme on a medical School Library service, Health Information and Libraries Journal 20,42-49.

Powell, C.A. and Case-Smith, J. (2003) Information literacy skills of occupational therapy graduates: a survey of learning outcomes, Journal of the Medical Library Association 91(4), 468-477.

Powis, C. (2004) Shouting into the wind - who has the most influence over first year undergraduate information literacy? Paper given at Yorkshire Universities Information Skills Group workshop Information Skills: Does it work June $21^{\text {st }} 2004$

Roberts, S. (2001) Smaller can be beautiful: maximising electronic journals in small to medium-sized institutions, Serials 14(1), 33-36.

Sweeney, L.J. (1999) Confronting crisis: the importance of measuring the use of paper journals in academic libraries, New Library World 100,79-79.

Tenopir, C. (2003) What User Studies tell us, Library Journal 128(14), 32-33.

Third Annual Report of the JUBILEE Project (2002?) URL:

http://online.northumbria.ac.uk/faculties/art/information_studies/Imri/rarea/im/hfe/jub /hfjubilee.htm [Accessed 14/06/04] 
Wozar, J.A. and Worona, P.C. (2003) The use of online information resources by nurses, Journal of the Medical Library Association 91(2), 216-221

WORD COUNT : 6049 